\title{
Changes in Carotenoids and Their Fatty Acid Esters in Banana Peel during Ripening
}

\author{
Achmad Subaglo and Naofumi Morita* \\ Laboratory of Food Chemistry, College of Agriculture, Osaka Prefecture University, Gakuen-cho 1-1, Sakai, Osaka 593, Japan
}

Received November 18, 1996; Accepted May 19, 1997

\begin{abstract}
Changes in carotenoids and their fatty acid esters in banana peel during ripening were investigated using a combination of an alumina column and high-performance liquid chromatography (HPLC). The level of total carotenoids decreased during the early stage of ripening but recovered again to the level of green fruit. Carotenoids belonging to both the $\alpha$ - and $\beta$-carotene categories decreased in the early stage of ripening, then the $\alpha$-carotene category, especially lutein, increased significantly, but not the $\beta$-carotene category. Because the amount of $\alpha$-cryptoxanthin was quite small, the process of hydroxylation of $\alpha$-carotene to lutein, where $\alpha$-cryptoxanthin was the intermediate product, seemed to occur quickly. Free lutein was easily esterified to lutein monoester and then was gradually further esterified to lutein diester; the amount of free, monoester and diester of lutein was about 20 , 60 and $20 \%$ of total lutein, respectively after 4 days' storage. A small amount of isolutein, which is an epoxy of lutein, was observed and all isolutein was in the monoester form after 4 days' storage, but no diester form was detected.
\end{abstract}

Keywords: Musa AAA group, banana, carotenoids, carotenoid fatty acid esters, ripening

The color of fruit peel, like its texture, is closely associated with its quality. Such a phenomenon also occurs in banana where the color of the peel changes from green to yellow during ripening. The most important compounds responsible for the change in peel color are chlorophylls and carotenoids (Gross \& Flugel, 1982; Tucker, 1993). In a previous paper, we reported that carotenoids in banana peel are in the $\alpha$-carotene category and are mainly composed of lutein, $\alpha-\beta$-carotene, violaxanthin, auroxanthin, neoxanthin, isolutein, and $\alpha^{-}, \beta$ cryptoxanthin (Subagio et al., 1996). This composition is close to the composition of chloroplast carotenoids; therefore, the carotenoid plastid in banana peel is presumed to be a gerontoplast which is a kind of chromoplast developed from chloroplasts (Ryberg et al., 1993). We also reported that the oxygenated carotenoids mostly existed in 2 states: as a free fatty acid and/or as a monoester of fatty acid, except that lutein existed in 3 states: free, mono and/or diester of a fatty acid as reported by Gross et al. (1976). The major fatty acids in the oxygenated carotenoids were myristate, laurate, palmitate and caprate.

Gross and Flugel (1982) reported only the change in total carotenoids without discussion of the changes in individual carotenoids and their fatty acid esters. Furthermore, they reported that the level of total carotenoids in banana peel during ripening decreased to half the original amount, followed by gradual esterification, and then again reached the level of the green fruit, whereas chlorophylls decreased rapidly, being absent in the ripe fruit. This metabolism is unique, because in other fruits, such as grapefruit, lemon and roman berry, the concentration of carotenoids decreases when the chlorophylls disappear (Yokohama \& Vandercook, 1967; Yokohama \& White, 1967; Valadon \& Mummery, 1972), whereas in fruits, such as citrus, pepper and tomato, the

\footnotetext{
* To whom correspondence should be addressed.
}

concentration of carotenoids increases when chlorophylls disappear (Goodwin, 1980).

For the above reason, further investigation of the changes in carotenoids and their fatty acid esters in banana peel is needed to clarify the mechanism of ripening in bananas. This will also help to understand the pathway of biosynthesis of carotenoid fatty acid esters during ripening in fruit. In this paper, we attempted to study the changes in carotenoids and their fatty acid esters in banana peel during ripening.

\section{Materials and Methods}

Materials Immature green bananas (Musa AAA group, Cavendish subgroup cv. Giant Cavendish) were obtained from a banana center, which had imported them from Ecuador. The chemicals and solvents used were of guaranteed grade. Alumina oxide was obtained from Merck (California, USA). Lutein was purified as described previously (Subagio et al., 1996). The purity of lutein was checked by HPLC, thin layer chromatography (TLC), photometry and liquid chromatography-mass spectrometry (LC-MS), and the concentration was calculated using $E_{445 \mathrm{~mm}, \mathrm{lcm}}^{1 \%}(\mathrm{EtOH})=2550$ (Davies, 1976).

Banana preparation Bananas were prepared as described by Toyosawa et al. (1994) with some modifications. Green bananas obtained from the banana center were placed in a polyethylene bag $(\operatorname{size}=50 \mathrm{l})$ which was then closed tightly. Ethylene gas $(5 \mathrm{ml})$ was introduced into the bag. The bananas were stored at $20^{\circ} \mathrm{C}$ for $24 \mathrm{~h}$. Then the bag was opened, and bananas were kept in the same room until analysis. The analysis was done after 2, 4, 5 and 7 days of storage, and also on 0 day (before ethylene treatment).

Qualitative and quantitative determinations of carotenoids and their fatty acid esters Qualitative and quantitative determinations of carotenoids were done as described previously (Subagio et al., 1996). Carotenoids from banana 
peel were extracted with acetone : ethanol : hexane $(1: 1: 2)$. The extracts were fractionated into 5 fractions using alumina (grade IV) column chromatography and further separated using HPLC as described by Gregory et al. (1987) and Philip and Chen (1988). Characterization of carotenoids was done in chemical tests, TLC, photometry and retention time in HPLC. LC-MS was used to determine the lutein. The quantitative determination of carotenoids was done by HPLC, and lutein was used as an external standard. The data were expressed as an average of 3 determinations.

Color determination To evaluate the ripening process of banana peel color, a chromameter (model CR-100, Minolta, Osaka) was used: illuminant $\mathrm{C}$ for daylight, and the chromameter was used in the averaging mode with 10 replications per sample. The instrument was calibrated externally with a standard white tile, and the tristimulus coordinates $L^{*}, a^{*}$, and $b^{*}$ (CIE color scale) system was applied to express the tone of the color. Values of $L^{*}$ indicate brightness or darkness, and values of the hue angle $\left(\tan ^{-1} b^{*} /\right.$ $\left.a^{*}\right)$ indicate the sample color where each hue angle corresponds to a particular color: $0^{\circ}$, red; $90^{\circ}$, yellow; $180^{\circ}$, green; and $270^{\circ}$, blue (McGuire, 1992).

\section{Results}

The color of the banana peels changed gradually during ripening (Table 1). The calculated hue angle decreased from $119.7^{\circ} \pm 0.6$ of the value before ethylene treatment to $92.7^{\circ} \pm 1.5$ after 7 days' storage. This proved that the color of the banana peels changed from yellowish green to yellow after 7 days' storage. Furthermore, the $L^{*}$ value increased gradually from $57.1 \pm 3.2$ of the value before ethylene treatment to $71.5 \pm 2.6$ after 5 days' storage but did not change between 5 and 7 days' storage, indicating that the brightness of the banana peel increases during ripening.

The total carotenoids decreased in the early stage of ripening from $364.2 \pm 23.6 \mu \mathrm{g} / 100 \mathrm{~g}$ of the value before ethylene treatment to $236.6 \pm 22.0 \mu \mathrm{g} / 100 \mathrm{~g}$ after 2 days' storage, then recovered again to the level of green fruit after 5 days' storage (Fig. 1) as reported by Gross and Flugel (1982).

Regarding the type of ionone ring of carotene, the carotenoids of banana peel were classified into 2 categories: $\alpha$ - and $\beta$-carotene categories. The carotenoids belonging to the $\alpha$-carotene category have $\beta, \varepsilon$-ionone rings, including $\alpha$ carotene, $\alpha$-cryptoxanthin, lutein, isolutein, and chrysanthemaxanthin, whereas the $\beta$-carotene category has $\beta, \beta$-ionone rings, including $\beta$-carotene, $\beta$-cryptoxanthin, violaxanthin, auroxanthin, luteoxanthin, neoxanthin and neochrome (Subagio et al., 1996). Figure 1 also shows that the $\alpha$-carotene

Table 1. Changes in the color of banana peel during ripening.

\begin{tabular}{ccc}
\hline Time (day) & $L^{*}$ value & Hue angle $\left(^{\circ}\right)$ \\
\hline 0 & $57.1 \pm 3.2$ & $119.7 \pm 0.6$ \\
2 & $63.0 \pm 3.5$ & $115.2 \pm 3.0$ \\
4 & $69.1 \pm 2.8$ & $101.4 \pm 4.5$ \\
5 & $71.7 \pm 2.8$ & $95.8 \pm 2.3$ \\
7 & $71.5 \pm 2.6$ & $92.7 \pm 1.5$ \\
\hline
\end{tabular}

$L^{*}$ value and hue angle ( $\left.{ }^{\circ}\right)$ were determined using a chromameter CR-100 (Minolta). See Materials and Methods for details. category showed a trend similar to total carotenoids in that they decreased in the early stage of ripening and increased again to the initial level of green fruit. In contrast, the $\beta$-carotene category decreased gradually in the early stage, then increased slightly in the middle stage of ripening, and remained at only half of the green fruit level after 7 days' storage.

Figure 2 shows the changes in three major carotenoids: total luteins including free, monoester and diester forms, and $\alpha$-and $\beta$-carotene. The concentration of $\beta$-carotene, which is the major component of the $\beta$-carotene category was $144.2 \pm$ $6.0 \mu \mathrm{g} / 100 \mathrm{~g}$ before ethylene treatment and dropped to about half this level after 7 days' storage. Up to the 4 th day of storage, $\beta$-carotene was the dominant carotenoid, but after that, lutein became dominant. Total lutein decreased distinctly during the early stage of ripening from $91.8 \pm 7.0 \mu \mathrm{g} / 100 \mathrm{~g}$ of the value before ethylene treatment to $38.0 \pm 11.0 \mu \mathrm{g} / 100 \mathrm{~g}$ after 2 days' storage, then increased again to about twice the green stage level after 5 days' storage. However, $\alpha$-carotene which is converted to lutein (Britton, 1976), did not change in the same way that total lutein changed. $\alpha$-Carotene, like $\beta$-carotene, decreased gradually, falling to half its original level after 7 days' storage. This phenomenon can be explained

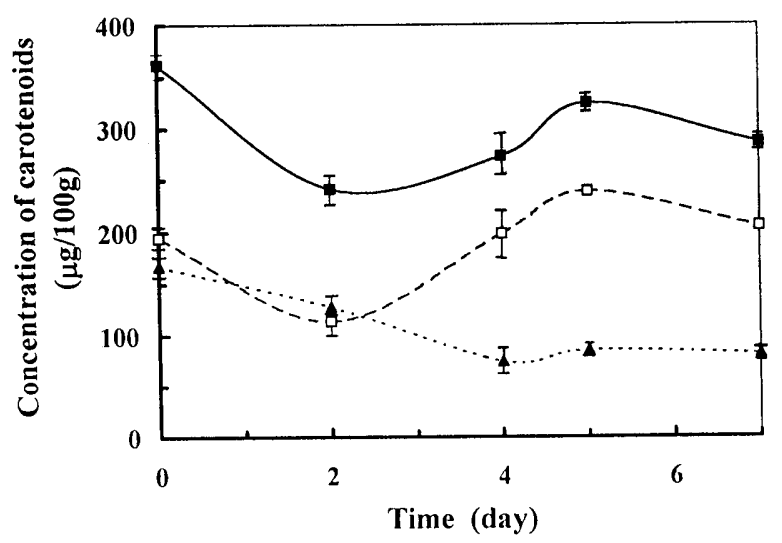

Fig. 1. Changes in total carotenoids ( $\mathbf{\square}), \alpha$-carotene category $(-$ and $\beta$ carotene category $(\mathbf{A})$ in banana peel during ripening.



Fig. 2. Changes in three major carotenoids in banana peel during ripening. ๑, total lutein; $\mathbf{\square}, \alpha$-carotene; $\triangle, \beta$-carotene. 
in more detail by comparing the change in each carotenoid belonging to the $\alpha$-carotene category.

To better understand this phenomenon, we tested the change in each carotenoid belonging to the $\alpha$-carotene category in banana peel during ripening as shown in Fig. 3. $\alpha$-Carotene decreased gradually to half of the green fruit level after 7 days' storage. Although $\alpha$-cryptoxanthin (monohydroxy $\alpha$-carotene) increased sharply and reached a peak after 2 days' storage and then decreased sharply, the absolute amount was very low $(5.1 \pm 0.5 \mu \mathrm{g} / 100 \mathrm{~g})$ after 2 days' storage. On the other hand, the total amount of lutein (dihydroxy $\alpha$-carotene) decreased during the early stage of ripening and then increased again until it reached twice the green stage level after 5 days' storage. In addition, the observed epoxy forms of the $\alpha$-carotene category were isolutein (mono-5,6 epoxy, dihydroxy $\alpha$-carotene) and chrysanthemaxanthin (mono-5,8 epoxy, dihydroxy $\alpha$-carotene) which is observed in trace amounts. The amount of total isolutein increased gradually and reached at $3.6 \pm 0.2 \mu \mathrm{g} / 100$ $\mathrm{g}$ after 7 days' storage, but this amount was not high compared with those of $\alpha$-carotene and lutein.

Figure 4A shows the changes in lutein and its fatty acid ester in banana peel during ripening. Before ethylene treatment, all of the lutein $(91.8 \pm 7.0 \mu \mathrm{g} / 100 \mathrm{~g})$ was in the free form, and no lutein fatty acid ester was observed. Although total lutein began to increase quickly after 2 days' storage, free lutein did not increase distinctly and remained at only $28.5 \pm$ $5.2 \mu \mathrm{g} / 100 \mathrm{~g}$ after 7 days' storage. On the other hand, lutein monoester increased to more than twice the amount of free lutein after 4 days' storage $(101.3 \pm 8.1 \mu \mathrm{g} / 100 \mathrm{~g})$. Lutein diester also slightly increased after 2 days' storage and reached $41.2 \pm 6 \mu \mathrm{g} / 100 \mathrm{~g}$ after 7 days' storage.
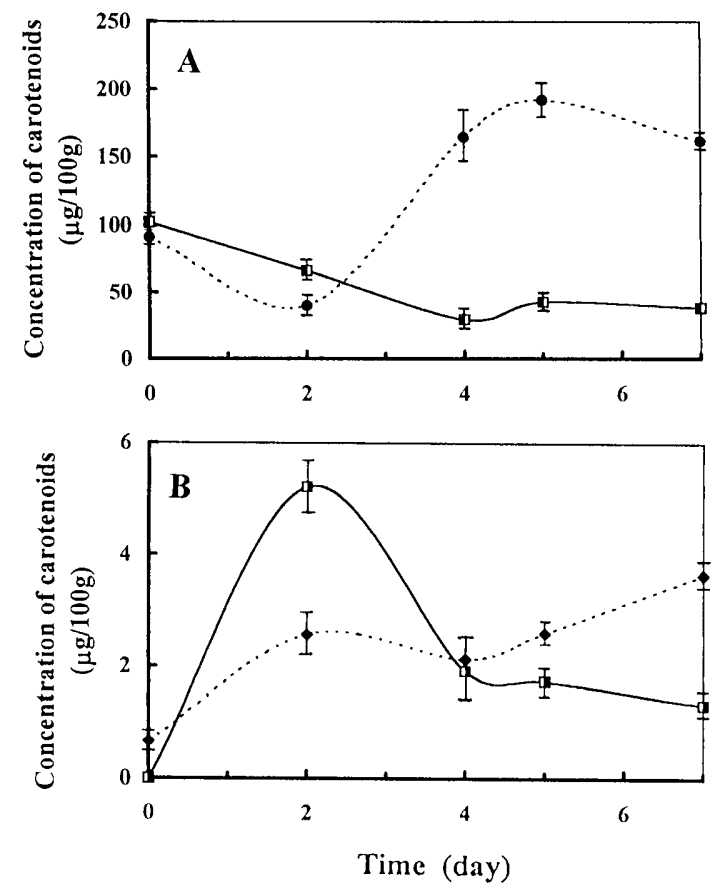

Fig. 3. Changes in each carotenoid of $\alpha$-carotene category in banana peel during ripening. (A): $\bullet$, total lutein; $\mathbf{D}, \alpha$-carotene. (B): $\bullet$, total isolutein; $\mathbf{\square}$, $\alpha$-cryptoxanthin.
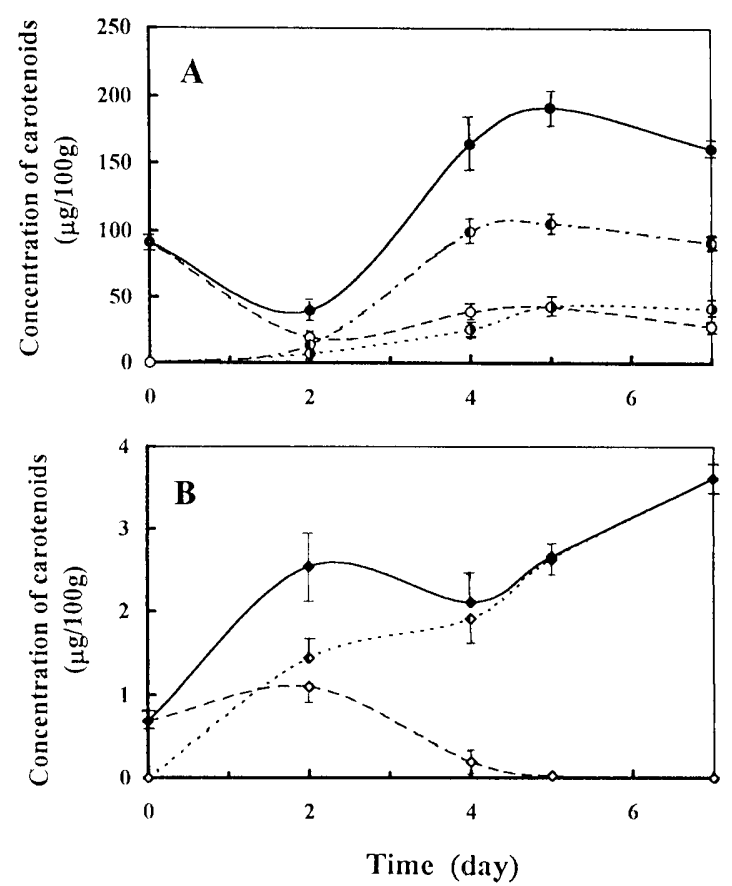

Fig. 4. Esterification of lutein $(A)$ or isolutein $(B)$ in banana peel during ripening. (A): - total lutein; 9 , free lutein; $\mathbf{O}$, lutein monoester; $\mathbf{O}$, lutein diester. (B): $\diamond$, total isolutein, $\diamond$, free isolutein; $\square$, isolutein monoester.

Like lutein, all of the isolutein was in the free form, i.e., none was in the fatty acid ester form, before ethylene treatment, therefore no isolutein fatty acid ester was observed (Fig. 4B). Although the total amount of isolutein increased slightly during ripening, free isolutein decreased from $0.7 \pm 0.2 \mu \mathrm{g} /$ $100 \mathrm{~g}$ to zero after 4 days' storage. On the other hand, isolutein monoester increased continuously from zero to $3.6 \pm 0.2 \mu \mathrm{g} /$ $100 \mathrm{~g}$ after 7 days' storage.

\section{Discussion}

During ripening, the color of the banana peel changed gradually from yellowish green to yellow, and the brightness increased. The decrease in the degree of green color may be due to degradation of chlorophyll, and at the same time, the generation of the yellow color and also the brightness of color of the carotenoids would be appearing (Gross \& Flugel, 1982). These results suggested that the bananas used in this study were well ripened.

The total amounts of carotenoids decreased during the early stage of ripening but then returned to the level in green fruit. The decrease in the amount of carotenoids in the early stage of ripening may correspond to the dissociation of the granal system during the chloroplast-chromoplast transformation as was also reported to occur in Lycopersicon esculentum fruits (Laval-Martin et al., 1975). In Euonymus, as the chlorophyll degrades, the structure of aging chloroplasts resembles that of chromoplasts (Ikeda, 1979). Blackbourn et al. (1990a) reported that over the course of ripening, the plastids of banana peel appeared to swell and change in shape from an elliptical to a spherical shape to form chromoplasts. In the middle stage of banana ripening, after the chromoplasts had been assembled, the amount of total 
carotenoids increased again. Gross et al. (1976) reported that the composition of carotenoids in banana peel is close to that of the chloroplast-type found in leaves, where carotenoids of the $\alpha$-carotene category are dominant. Our study showed that during ripening, carotenoids of the $\alpha$-carotene category changed more prominently than those of the $\beta$-carotene category, and biosynthesis of the $\alpha$-carotene category rapidly occurred in the middle stage of ripening, but not for the $\beta$-carotene category. This fact proved that the composition of carotenoids in banana peel is close to that of the chloroplast carotenoids where the $\alpha$-carotene category is dominant.

Many investigators (Britton, 1976; Goodwin, 1980; Misawa, 1995) reported that after cyclization, oxygenation in carotenes commonly occurs through the addition of a hydroxyl group and/or epoxy group. The free lutein was formed from hydroxylation of $\alpha$-cryptoxanthin, which is the intermediate component which is derived from $\alpha$-carotene. After ethylene treatment, the total amount of lutein formed increased significantly and reached more than twice the level in green stage. This fact coincided with the result that the amount of $\alpha$-cryptoxanthin observed was small. Furthermore, the total lutein increased during ripening, but the amount of free lutein decreased. This may be due to the fact that the free lutein is esterified easily to lutein monoester and is also converted to isolutein by epoxidation. Lutein monoester was then gradually further esterified to the diester form. With regard to the $\alpha$-carotene category, lutein has 2 different ionone rings, namely the $\beta$ - and $\varepsilon$-ionone rings, both of which contain one $\mathrm{OH}$ group. In nature, a fatty acid of lutein monoester exists in the $\beta$-ionone ring as previously reported (Khachik et al., 1988). From this viewpoint, the fact that the amount of lutein diester formed was not as great as the amount of lutein monoester suggests that the $\mathrm{OH}$ group of the $\beta$-ionone ring is more easily esterified than the $\mathrm{OH}$ group of the $\varepsilon$-ionone ring. This fact agreed with the result that, after 4 days' storage, the amount of free, monoester and diester of lutein was about 20,60 and $20 \%$ of the total lutein, respectively.

Free isolutein, like free lutein, seems to be easily esterified to the monoester form, and isolutein monoester may also be formed from lutein monoester by epoxidation. Because the amount of free isolutein formed was small, the amount of monoester that was observed was also not very high. Furthermore, no isolutein diester was observed in banana peel. This may be due to 1) the amount of isolutein that formed was small, and/or 2) the activity of the enzyme that esterifies the monoester to the diester is reduced, because the $\mathrm{OH}$ group of the $\beta$-ionone ring that contains the epoxy group may become non-polar to some extent.

Fatty acid esters of oxygenated carotenoids rapidly increased in the middle stage of ripening and decreased only slightly after 7 days' storage, whereas the free oxygenated carotenoids decreased during ripening. Furthermore, both lutein and isolutein ester were not observed before the ethylene treatment. These findings indicate that esterification occurs only during ripening and increases along with the degree of ripening. The esterification of the oxygenated carotenoids may be correlated with an ultrastructural change in which chloroplasts are turned into chromoplasts (Gross \&
Flugel, 1982). During ripening, chloroplast thylakoid membranes might be degraded gradually, releasing fatty acids in the process (Blackbourn et al., 1990b). At the same time, the oxygenated carotenoids would be gradually esterified by the released fatty acids (Subagio et al., 1996).

Based on the present results, the formation of fatty acid esters of carotenoids may correlate with the degree of ripening of banana pulp. The more fatty acid esters of carotenoids that are formed, the higher the degree of ripening. Therefore, the stage of ripening could be estimated from an analysis of the esterification of $\mathrm{OH}$ groups in oxygenated carotenoids.

Acknowledgments The authors are indebted to Dr. T. Wasino, San-Ei-Gen, Co., Ltd. (Osaka), for providing the carotene samples and for valuable suggestions on this research. Achmad Subagio thanks the Osaka Foundation of International Exchange (OFIX) for supporting his study in Japan.

\section{References}

Blackbourn, H.D., Jeger, M.J., John, P. and Barber, J. (1990a). Inhibition of degreening in the peel of banana ripened at tropical temperature. III. Changes in plastid ultrastructure and chlorophyllprotein complexes accompanying ripening in bananas and plantains. Ann. Appl. Biol., 177, 147-161

Blackbourn, H.D., Jeger, M.J., John, P. and Barber, J. (1990b) Inhibition of degreening in the peel of banana ripened at tropical temperature. IV. Photosynthetic capacity of ripening bananas and plantains in relation to changes in the lipid composition of ripening banana peel. Ann. Appl. Biol., 177, 163-174.

Britton, G. (1976). Later reactions of carotenoid biosynthesis. Pure Appl. Chem., 47, 223-236.

Davies, B.H. (1976). Carotenoids. In "Chemistry and Biochemistry of Plant Pigments," ed. by T.W. Goodwin. Academic Press, London, New York and San Francisco, Vol. II, pp. 38-165.

Goodwin, T.W. (1980). "The Biochemistry of the Carotenoids." Chapman and Hall, London, $377 \mathrm{pp}$.

Gregory, G.K., Chen, T.-S. and Philip, T. (1987). Quantitative analyses of carotenoid and carotenoid fatty acid esters in fruits by HPLC: red bell peppers. J. Food Sci, 52, 1071-1073.

Gross, J. and Flugel, M. (1982). Pigment change in peel of the ripening banana (Musa cavendishi). Gartenbauwiss, 47, 62-64

Gross, J., Carmon, M., Lifshitz, A. and Costes, C. (1976). Carotenoids of banana pulp, peel, and leaves. Lebensm.-Wiss.u.-Technol., 9, 211214.

Ikeda, T. (1979). Electron microscopic evidence for the reversible transformation of Euonymus plastids. Bot. Mag. (Tokyo), 92, 2330.

Khachik, F., Beecher, G.R. and Lusby, W.R. (1988). Separation and identification of carotenoids and carotenol fatty acid esters in some squash products by liquid chromatography. 2. Isolation and characterization of carotenoids and related esters. J. Agric. Food Chem. 36, 938-946.

Laval-Martin, D., Quennemet, J. and Moneger, R. (1975). Pigment evolution in Lycopersicon esculentum fruits during growth and ripening. Phytochemistry, 14, 2357-2362.

McGuire, R.G. (1992). Reporting of objective color measurement Hort Sci., 27, 1254

Misawa, N. (1995). Study on carotenoid biosynthesis using the methods of natural products chemistry, molecular biology and metabolic engineering. Nippon Nôgeikagaku Kaishi, 69, 1567-1572 (in Japanese)

Philip, T. and Chen, T.-S. (1988). Quantitative analyses of major carotenoid fatty acid esters in fruits by liquid chromatography: persimmon and papaya. J. Food Sci., 53, 1703-1706.

Ryberg, H., Ryberg, M. and Sundqvist, C. (1993). Plastid ultrastructure and development. In "Pigment-Protein Complexes in Plastids: Synthesis and Assembly," ed. by C. Sundqvist \& M. Ryberg. Academic Press, London and New York, pp. 25-62. 
Subagio, A., Morita, N. and Sawada, S. (1996). Carotenoids and their fatty acid esters in banana peel. J. Nutr. Sci. Vitaminol., 42, 553-566.

Toyosawa, I., Chachin, K., Hamauzu, Z., Fujikawa, E., Miyagawa, K. and Yamauchi, N. (1994). "Experimental Methods of Food Processing," 2nd ed., Kagakudoujin, Kyoto, Japan, pp. 67-69 (in Japanese).

Tucker, G.A. (1993). Introduction, In "Biochemistry of Fruit Ripening," ed. by G.B. Seymour, J.E. Taylor \& G.A. Tucker. Chapman \& Hall, London, Glasgow, New York, Tokyo, Melbourne and
Madras, pp. 1-51.

Valadon, R.F.G. and Mummery, R.S. (1972). Carotenoids of rowan berries. Ann. Bot., 36, 471-474.

Yokohama, H. and Vandercook, C.E. (1967). Citrus carotenoids I. Comparison of carotenoids of mature-green and yellow lemon. $J$. Food Sci., 32, 42-48.

Yokohama, H. and White, M.J. (1967). Carotenoids in the flavedo of march grapefruit. J. Food Chem., 15, 693-699. 